\title{
Hydrogen-induced Brittle Fracture in Nickel based Alloy 82 Weld Metal
}

DOI:

10.1016/j.corsci.2019.03.021

Document Version

Accepted author manuscript

Link to publication record in Manchester Research Explorer

\section{Citation for published version (APA):}

Platt, P., Sayers, J., Horner, D. A., Barrow, A., \& Engelberg, D. (2019). Hydrogen-induced Brittle Fracture in Nickel based Alloy 82 Weld Metal. Corrosion Science. https://doi.org/10.1016/j.corsci.2019.03.021

\section{Published in:}

Corrosion Science

\section{Citing this paper}

Please note that where the full-text provided on Manchester Research Explorer is the Author Accepted Manuscript or Proof version this may differ from the final Published version. If citing, it is advised that you check and use the publisher's definitive version.

\section{General rights}

Copyright and moral rights for the publications made accessible in the Research Explorer are retained by the authors and/or other copyright owners and it is a condition of accessing publications that users recognise and abide by the legal requirements associated with these rights.

\section{Takedown policy}

If you believe that this document breaches copyright please refer to the University of Manchester's Takedown Procedures [http://man.ac.uk/04Y6Bo] or contact uml.scholarlycommunications@manchester.ac.uk providing relevant details, so we can investigate your claim.

\section{OPEN ACCESS}




\title{
Hydrogen-induced Brittle Fracture in Nickel based Alloy 82 Weld Metal
}

\author{
P. Platt ${ }^{\mathrm{a}}$, J. Sayers ${ }^{\mathrm{b}}$, D. A. Horner ${ }^{\mathrm{c}}$, A. Barrow ${ }^{\mathrm{c}}$, D. L. Engelberg ${ }^{\mathrm{a}}$ \\ ${ }^{a}$ The University of Manchester, School of Materials, Materials Performance Centre, Corrosion and \\ Protection, The Mill, M13 9PL \\ ${ }^{b}$ University of Oxford, Department of Materials, Parks Road, Oxford, OX1 3PH \\ ${ }^{c}$ Rolls-Royce, PO Box 2000, Raynesway, Derby, DE21 7BE
}

\begin{abstract}
Alloy 82 weld metal is sensitive to hydrogen assisted fracture and low-temperature crack propagation. Novel ex-situ and in-situ mechanical testing, and hydrogen charging techniques were combined with post-test fractography to investigate this effect. Electrolytic hydrogen charging followed by mechanical testing confirmed a reduction in the elongation to failure and fracture strength. The reduction in mechanical behaviour correlated with the transition from ductile to inter-granular (IG), inter-dendritic (ID), and cleavage-type brittle fracture modes. In-situ low temperature crack propagation testing at $54^{\circ} \mathrm{C}$ confirmed the presence of brittle inter-granular fracture as a result of hydrogen absorbed during exposure to the aqueous test environment.
\end{abstract}

\section{Introduction}

Nickel-chromium based Alloy 82 is used as a weld material in power generation systems to join Alloy 600 components [1,2], and dissimilar ferritic-austenitic joints [3]. For nuclear pressurised water reactors this includes inlet and outlet piping and nozzle pressure vessel connections. Alloy 82 and Alloy 182 offer a good combination of corrosion resistance and ductility, with a thermal expansion coefficient in-line with the structural materials being welded. However, nickel-chromium based welds are sensitive to a sub-critical brittle crack propagation in a low temperature aqueous environment termed Low Temperature Crack Propagation (LTCP).

Assessment of LTCP centres typically on the impact of hydrogen on the fracture toughness $\left(\mathrm{J}_{\mathrm{IC}}\right)$ and fracture resistance $\left(\mathrm{J}_{\mathrm{Q}}\right)$ of the material [4-8]. Fracture resistance is used when testing does not meet the requirements of standards such as ASTM 1820-01 [9,10], for example if failure does not result in an even crack front. It has been shown that nickel-chromium welds can demonstrate a significant reduction in fracture toughness or resistance when exposed to hydrogen enriched water $\left(30-180 \mathrm{~cm}^{3}\right.$ $\mathrm{H}_{2} / \mathrm{kg} \mathrm{H} \mathrm{H}_{2} \mathrm{O}$ ) in the temperature range of 50 to $150{ }^{\circ} \mathrm{C}[4,11-14]$. It is also a requirement that the material contains a pre-existing crack, and that the loading or displacement rate is slow (e.g. $\sim 0.1$ $\mathrm{mm} / \mathrm{h}$ ) [4,11-14]. Mills et al. deemed that welds exhibiting values lower than $\sim 30 \mathrm{~kJ} / \mathrm{m}^{2}$ were at the highest risk, as fracture could occur for loading levels lower than that required for plastic yielding of the 
material [4-6]. This problem is of particular relevance when a reactor goes through a shut-down phase and materials contract during cooling.

A key aspect of the different LTCP tests found in literature is the use of hydrogen pre-charging, this can separate out the effect of hydrogen pre-existing in a material [4], and hydrogen absorbed locally at the crack surface [9]. One pre-charging approach is to use hydrogen rich water $\left(30-100 \mathrm{~cm}^{3} \mathrm{H}_{2} / \mathrm{kg}\right.$ $\left.\mathrm{H}_{2} \mathrm{O}\right)$, at PWR operating temperatures $\left(300-320^{\circ} \mathrm{C}\right)$, for time ranges of $24-1000 \mathrm{~h}[11,14]$. The studies that use this approach did not see any significant charging effect, with subsequent microstructural analysis indicating very low hydrogen concentrations of $1 \pm 0.5$ wt.ppm [14]. It has been suggested that exposure to elevated temperature pre-charging conditions could actually decrease the amount of trapped hydrogen [15]. Other researchers pre-charged specimens using high purity hydrogen gas for either 6 weeks at $360^{\circ} \mathrm{C}[4,12]$, or $1-4 \mathrm{~h}$ at $704^{\circ} \mathrm{C}[16]$. These approaches produced hydrogen concentrations in the range of 24-74 wt.ppm, resulting in a noticeable reduction in fracture toughness and fractographic evidence of inter-granular failure $[4,12,16]$.

In the absence of hydrogen, crack propagation in these studies is ductile and trans-granular, raising the question of why embrittlement takes the form of inter-granular failure. Coarse and fine niobium and titanium rich $\mathrm{MC}$ carbides have been observed and could act as hydrogen traps, releasing hydrogen ahead of an advancing crack tip $[4,15,16]$. However, these precipitates are present throughout the material, and not just at grain boundaries [2,4]. The precipitates that do form preferentially at grain boundaries are the chromium rich $\mathrm{M}_{23} \mathrm{C}_{6}$ carbides $[2,12,15,16]$. The formation of these precipitates is closely linked with the post weld heat treatment and in-service conditions. Grain boundary (GB) sensitisation of Alloy 182 welds has been observed with heat treatments of $615^{\circ} \mathrm{C}$ for $10-24 \mathrm{~h}$ and $450{ }^{\circ} \mathrm{C}$ for $200 \mathrm{~h}[17,18]$. Transmission electron microscopy (TEM) has indicated that these precipitates form preferentially along high angle grain boundaries (misorientation $>15^{\circ}$ ) [2], which could link with observations of a relatively high proportion of high angle grain boundaries and propensity for SCC along these boundaries in Alloy 182 welds [19]. However, caution must be used when attributing generalised trends to localised observations..

The work reported in this paper systematically investigates the impact of hydrogen pre-charging on Alloy 82 welds with a range of both ex-situ and in-situ tensile tests, in-situ optical microscopy and postfailure SEM fractography.

\section{Experimental}

The material used in this work was an Alloy 82 weld, with a nominal composition of $>67 \% \mathrm{Ni}, 18-22 \%$ $\mathrm{Cr},<3 \% \mathrm{Fe}, 2.5-3.5 \% \mathrm{Mn}, 2-3 \% \mathrm{Nb},<0.15 \% \mathrm{Si},<0.75 \% \mathrm{Ti},<0.5 \% \mathrm{Cu}$, and $<0.1 \% \mathrm{C}$ [2]. Two specimen geometries were used, comprising dog-bone tensile samples and single edge notched tensile specimens (SENT). The weld and sample extraction orientations are illustrated schematically in Fig.1. A set of tensile specimens were made with the surface parallel to the top face of the weld, with a 
rectangular gauge section of $1 \times 3 \mathrm{~mm}$, and a length of $28 \mathrm{~mm}$. The tensile specimens were taken from near the top of the weld, and the entire specimen was contained within the weld width.

The SENT samples were made with the surface parallel to the root-to-crown direction (Fig.1). They had a rectangular cross section of $1.5 \mathrm{~mm} \times 6 \mathrm{~mm}(\mathrm{t} \times \mathrm{w})$, with a $1.5 \mathrm{~mm}$ deep v-notch and a tip-radius of $0.2 \mathrm{~mm}$, giving a cross section of $1.5 \times 4.5 \mathrm{~mm}$. These specimens where taken from lower in the weld, so the loading grips were composed of the Heat Affected Zone (HAZ) and parent material.

One set of samples were polished to $1 / 4$ micron diamond paste surface finish, followed by OPS polishing (silica based oxide polishing solution), and electrolytic etching in 70 wt.\% phosphoric acid. For etching, a 304 stainless steel cathode was used, with an applied potential of 3-5 V for 10-20 seconds. Electron backscattered diffraction (EBSD) was carried out using a Quanta 650 electron microscope interfaced with a Nordlys EBSD detector from Oxford Instruments and AZtec V2.2 software for data acquisition. A $20 \mathrm{kV}$ accelerating voltage with a step size of $2.8 \mu \mathrm{m}$ was used to characterise the grain morphology on the side and surface of the weld.

\subsection{Hydrogen Charging and Characterisation}

Tensile samples and SENT specimens were electrolytically charged with hydrogen prior to testing. A common problem when charging in acidic solutions is the formation of cracks at the sample surface in the absence of any applied load, in line with the results shown in [20-22]. The approach that charged specimens with hydrogen without damaging the surface was a $\mathrm{pH}$ neutral $1 \mathrm{M} \mathrm{NaCl}$ solution, with a strong nitrogen purge prior to and during charging. To maximise the amount of hydrogen in the sample, and the depth to which hydrogen penetrates, all hydrogen charging was carried out at $\sim 75^{\circ} \mathrm{C}$, with an applied current density of $50 \mathrm{~mA} / \mathrm{cm}^{2}$.

For hydrogen baseline analysis of the Alloy 82 weld, three coupon samples with dimensions of $\sim 3 \mathrm{~mm}$ $\times 5 \mathrm{~mm} \times 1 \mathrm{~mm}$ were analysed. The total hydrogen concentration of each coupon was measured via melt extraction using an ELTRA OH-900. For this particular test weld batch a baseline concentration of $6.35 \pm 0.05$ wt.ppm was obtained. Hydrogen analysis by melt extraction was also carried out after electrolytically charging samples followed by tensile testing until failure. Post-mortem, one half of the broken sample was manually cut to produce three pieces for hydrogen concentration analysis. Hydrogen analysis was carried out within $1 \mathrm{~h}$ of the specimen failing. After analysis the value obtained for the piece including a fracture surface was used in the results.

Further information on the hydrogen trapping behaviour of this weld was obtained by using thermal desorption spectroscopy (TDS) [23]. TDS involves the heating of a sample whilst monitoring the evolution of the species from the surface with a mass spectrometer. The surface of the sample is measured by use of a pyrometer, and the heater temperature is monitored internally. The heater is separated from the sample by an aluminium nitride wafer $\sim 0.5 \mathrm{~mm}$ thick. The heating rate used here was $\sim 15 \mathrm{~K} / \mathrm{min}$. A modification to the electrolytic charging process was that the $1 \mathrm{M} \mathrm{NaCl}$ electrolytic 
solution was made up of $150 \mathrm{ml} \mathrm{H}_{2} \mathrm{O}$ and $100 \mathrm{ml} \mathrm{D}_{2} \mathrm{O}$ (deuteriated water). This approach was adopted to clearly differentiate between trap sites occupied as a result of the charging process and those preexistent in the material.

After electrolytic hydrogen charging all tensile and SENT samples were gently cleaned in acetone and de-ionised water. Tensile testing was performed using an Instron 5567 loading frame at a constant strain rate of $1 \times 10^{-5} \mathrm{~s}^{-1}$. For these tests an optical imaging system was in place, to observe the crack propagation direction with the applied strain measured via the cross-head displacement. All specimens were tested to failure, so that it was possible to define the ultimate tensile strength (UTS), the notch tensile strength (NTS), elongation to failure (\%), and embrittlement ratio. The embrittlement ratio is defined as the elongation to failure for an uncharged specimen divided by the elongation of the charged specimen. For this weld material maximum load defined the point at which elongation was controlled by the propagation of a dominant primary failure crack. As such, the elongation was based on the displacement point from which plastic yield occurs to the displacement point at maximum load. For an uncharged specimen complete tensile failure would occur after $\sim 7 \mathrm{~h}$ of mechanical testing, for an elongation of $\sim 25 \%$.

\subsection{In-situ LTCP Testing}

In order to study the impact of hydrogen absorbed at a crack surface, a small number of customised in-situ tests were carried out. This involved fitting an Instron 5567 load frame with an integrated low temperature autoclave unit, which encloses the sample and parts of the loading rods. The environment was controlled using a re-circulating water system, pressurised up to a maximum of 4 bar by feeding gas into the de-ionised water header tank. For hydrogen gas this led to a maximum concentration of $\sim 69 \mathrm{cc} / \mathrm{kg}$ in the solution. Three SENT specimens were prepared for these tests.

Preparation included formation of a fatigue pre-crack at the notch tip, using a BOSE fatigue tester with a load range of $840-1440 \mathrm{~N}(140-240 \mathrm{MPa})$, at a frequency of $20 \mathrm{~Hz}$. Fatigue pre-cracks of $\sim 600 \mu \mathrm{m}$ in length formed after $\sim 2 \times 10^{6}$ cycles. After pre-cracking, one sample surface was polished to a $1 / 4$ micron diamond paste surface finish, followed by OPS polishing, and electrolytic etching in $70 \mathrm{wt} \%$ phosphoric acid. This created a pattern at the specimen surface for carrying out optical observations.

For each in-situ test the system was purged with nitrogen on a low flow rate for 12-16 $\mathrm{h}$ at a test temperature of $\sim 54{ }^{\circ} \mathrm{C}$, with an applied strain rate of $0.05 \mathrm{~mm} / \mathrm{h}$. During the pre-soak period in the autoclave, a low load was applied to open the crack and allow hydrogen absorption. The parameters of the three in-situ test environments included, (i) DI water with 4 bar over-pressure of nitrogen (LTCP1, reference condition), (ii) 4 bar hydrogen over-pressure, pre-soaked for $\sim 3$ days at $\sim 74{ }^{\circ} \mathrm{C}$, and $\sim 1$ day at $\sim 54^{\circ} \mathrm{C}$ (LTCP 2), and (iii) 4 bar hydrogen over-pressure, $\sim 5$ days pre-soak at $\sim 74^{\circ} \mathrm{C}$, and $\sim 2$ days at $\sim 54^{\circ} \mathrm{C}($ LTCP3). 


\section{Results \& Discussion}

The microstructure of Alloy 82 is shown in Fig.2, illustrating the dendritic substructure revealed by the etching process. Fig. 3 demonstrates the surface of the SENT samples (side of the weld), and the tensile specimens (surface of the weld). The EBSD maps show that the morphology is highly heterogeneous, with an elongated appearance when viewed from the side, and highly tortuous grain boundaries when viewed from above. Both the dendritic substructure and grain morphology are a product of the way in which the solidification front moved through the weld during cooling [24,25]. Although the grain size appeared highly variable, qualitative assessment indicates cross-section diameters in the 500-700 $\mu \mathrm{m}$ range, with lengths typically greater than $1 \mathrm{~mm}$.

\subsection{Hydrogen Up-take}

Fig.4 shows the bulk hydrogen concentration plotted against the electrolytic hydrogen charging time. Although there is a strong degree of scatter, it can be seen that there is a clear increase in the overall hydrogen concentration with increasing charging time. The results for the thermal desorption spectroscopy can be seen in Fig.5. BaseH2 is the profile for a bare non-charged sample and as such this profile relates purely to hydrogen that is trapped in the material from the welding process. Charge. $\mathrm{H} 2$ and Charge. DH are the $\mathrm{H}_{2}$ and $\mathrm{DH}$ profiles for a sample electrolytically charged for $87.5 \mathrm{~h}$. Interpreting the data in Fig.4 indicates that this charging should have introduced bulk hydrogen concentration in the range of 200-250 wt.ppm hydrogen.

The position of each peak temperature is related to the binding of the hydrogen species to specific trap sites. What these profiles show is that two distinctive peaks are present, one of which only appears after hydrogen charging. As the low temperature peak $\left(\sim 270{ }^{\circ} \mathrm{C}\right)$ is only observed in the charged sample it is likely to result from hydrogen or deuterium occupying lattice sites as a result of the charging process. During the welding process, and the extended period of time that the weld has been exposed to the atmosphere, any pre-existing lattice hydrogen should have out-gassed.

In Fig. 5 the trap site at $\sim 400{ }^{\circ} \mathrm{C}$ is present in the as-received and hydrogen charged samples, indicating a relationship with strong trap sites. TDS carried out by Ahonen et al. indicated that the second peak at $\sim 400{ }^{\circ} \mathrm{C}$ represents the niobium rich MC carbides that are extremely common in Alloy 82 welds. [26]. These precipitates are incoherent with the parent matrix [26], and will form elastic strain fields with the parent matrix making them very strong hydrogen trap sites $[27,28]$. Although far less numerous, chromium rich $\mathrm{M}_{23} \mathrm{C}_{6}$ carbides form epitaxial coherent interfaces with the parent matrix, as observed in Alloy 82 welds [2], and in nickel based Alloy 690 [29]. This will make them weak, easily reversible hydrogen trap sites.

\subsection{Hydrogen Embrittlement Testing}


The elongation to failure based on the plastic deformation for samples decreased with increasing total hydrogen concentrations (Fig.6). For the tensile specimens, elongation dropped from $\sim 25 \%$ strain down to $\sim 2 \%$ strain with an increase in total hydrogen concentration of $\sim 50$ wt.ppm. To improve comparison with literature using other sample geometries, and for direct comparison between SENT and tensile specimens in this study, the embrittlement ratio has been calculated (Fig.7). The embrittlement ratio is the elongation to failure for a sample charged with hydrogen divided by a sample that has not been charged. Both specimen geometries demonstrate significant embrittlement with the total addition of $\sim 50$ wt.ppm hydrogen.

Fig.8 gives the engineering ultimate tensile stress (tensile specimens), and notched tensile stress (SENT samples), plotted against the overall hydrogen concentration. There is a clear reduction in both UTS and NTS with increasing total hydrogen concentration. With an increase in hydrogen concentration of $>50$ wt.ppm, the results demonstrate a reduction in the UTS from $595 \mathrm{MPa}$ to 485 $\mathrm{MPa}$, and a reduction in the NTS from $675 \mathrm{MPa}$ to $585 \mathrm{MPa}$. Qualitative comparison of Fig.6 and Fig.7 with Fig. 8 indicates that both the UTS/NTS and elongation to failure demonstrate a similar relationship with the analysed total hydrogen concentration. Additional qualitative assessment of the individual load-displacement curves indicated that rather than a noticable change in hardening behaviour, the embrittlement may be shifting the point at which maximum load (primary fracture) occurs on the hardening curve. The implication is that the hydrogen may not be accelerating the plastic deformation on the macro scale. However, without the true stress and strain, and prior homogenisation of the hydrogen, it is not possible to fully assess the impact of hydrogen on the yielding and hardening behaviour of the material.

Making the comparison with steels, a number of authors have demonstrated a reduction in ductility $[30,31]$, and a reduction in the notch tensile strength with increasing hydrogen concentration introduced electrolytically [23,32]. However, there are mixed results when observations are made on how the yield strength, hardening behaviour or ultimate tensile strength respond to the introduction of hydrogen [31].

\subsection{Microscopic Observation and Fractography}

Fig. 9 shows a notched specimen that had been pre-charged to a total hydrogen concentration of 64 wt.ppm, before and after $\sim 0.83 \mathrm{~mm}$ displacement. As the specimen had been polished and etched prior to pre-charging and testing the grain boundaries were apparent. This figure shows that the crack first propagates along a grain boundary, which can be correlated with the post-failure fracture surface shown in Fig.10 to demonstrate the appearance of a hydrogen induced inter-granular (IG) fracture surface. The relatively linear features in the vertical direction, and tortuous features in the horizontal direction, correlate well with the grain morphology illustrated in Fig.3. This is a very similar intergranular fracture surface demonstrated in LTCP based tests [4,5,12-14]. 
Fig. 11 shows the fracture of a sample pre-charged with $\sim 55$ wt.ppm hydrogen, initially the crack is inter-dendritic before joining with a grain boundary. For these samples the grains are elongated and run vertically with reference to the image. Fig.12 illustrates those regions of fracture surface that correlate with inter-dendritic (ID) and IG fracture in this sample. The jagged, horizontal features of the inter-dendritic fracture are similar in morphology and scale to the dendritic sub-structures highlighted by the etchant in Fig.2. Due to the nature of the sub-grain boundary, and the increased probability of carbide formation, ID fracture will be the most energetically favourable form of trans-granular fracture. In addition, fractography of LTCP test specimens by Ahonen et al. attributed similar features to ID fracture modes [26]. Hydrogen induced fracture has also been observed at sub-grain features such as twin boundaries in TWIP steels [33].

Fracture surfaces of tensile test specimens with the highest hydrogen concentrations also demonstrated regions of cleavage fracture. This is illustrated in Fig.13, for a tensile sample charged to a total hydrogen concentration of $\sim 126$ wt.ppm hydrogen, after charging at $\sim 75^{\circ} \mathrm{C}$ over a period of 55 h. Galliano et al. observed cleavage fracture after hydrogen charging of Alloy 718 , this was largely attributed to the trapping behaviour and interfaces associated with the $\mathrm{Y}^{\prime} / \mathrm{Y}^{\prime \prime}$ phases in the material [34]. Although these phases are not present in Alloy 82, it is noteworthy that this fracture mode was only observed up to $150^{\circ} \mathrm{C}$ and was not present when testing at $320^{\circ} \mathrm{C}$. There is also some evidence for cleavage type fracture during low temperature SCG testing of electrolytically charged IN625 and IN718 [35].

Fig.14 is a collage of several SEM images, with the sample surface on the left edge, the hydrogen gradient will decrease as you move from left to right. Hence, it can be seen that as the concentration is reduced the fracture mode changes from cleavage, to ID, to IG / ductile dimpled on the right hand side of the image. However, it must be noted that these fracture modes did not form as consistent measurable layers across the specimen cross-section. This is likely a result of the heterogeneous nature of the weld microstructure and potentially the charging process itself.

The shift in fracture modes with increasing total hydrogen concentration can be correlated with the elongation to failure. As highlighted in Fig.15, with little or no additional hydrogen the fracture surface demonstrated only ductile failure. As the hydrogen concentration was increased more IG fracture, and then eventually small areas of ID fracture, became apparent. For samples with highest hydrogen concentrations, where elongation is very low and almost independent of the total hydrogen concentration, cleavage type fracture surfaces could be observed.

\subsection{In-Situ LTCP Testing}

Using the Instron 5567 load frame fitted with a low temperature autoclave and re-circulating water system it was possible to produce three in-situ LTCP tests. Two of these tests were carried out in solutions containing hydrogen concentrations of $\sim 69 \mathrm{cc} / \mathrm{kg}$ in the solution. The combination of fatigue 
pre-cracking the specimens, and using a slow displacement rate of $0.05 \mathrm{~mm} / \mathrm{hr}$ allowed for hydrogen absorption into the material at the crack tip during a pre-soak hold and during the test. Pre-soak time was modified to allow more hydrogen to be absorbed locally at the crack surface. No electrolytic charging was applied to the in-situ LTCP test specimens.

The load-displacement data for the tests is shown in Fig.16. As the length of the pre-cracks and specimen geometries were the same there should not be any variation in the stress concentration between the tests. Optical imaging could not be carried out during crack growth for these tests. However, these observations indicated that maximum load is the point at which the fatigue pre-crack begins to propagate. It can be seen that the load required for crack propagation is reduced when the aqueous environment is charged with hydrogen (LTCP $2 \& 3$ ). Although the number of test conditions is limited, it also appears that this load is reduced further with an increase in the pre-soak time period. Increasing the pre-soak time will enable a greater amount of hydrogen to be absorbed locally at the exposed crack tip and should therefore increase the hydrogen embrittlement. The reduction in the load required to initiate crack propagation, and the displacement required for complete fracture, is supported by the fracture resistance testing carried out on Alloy 600, Alloy 690, EN82H and EN52 by Mills \& Brown [4,12]. These findings also relate well with the SCG testing carried out by Hicks \& Altstetter, on IN625 and IN716 [35].

Fractography demonstrated that the sample tested in a nitrogen rich environment had a smaller crosssectional area and a highly dimpled fracture surface, both indicative of plastic failure. For the sample tested in hydrogen rich DI water (LTCP3), very little necking was evident and the fracture surface indicated localised regions of hydrogen embrittled grain boundary fracture (Fig.17). This is based on comparison with inter-granular fracture surfaces in other LTCP based tests [4,5,12-14], and hydrogen embrittled grain boundary fracture in this study (Fig.10 \& Fig.12).

\subsection{Comparing HE and LTCP Fractures}

Testing of ex-situ hydrogen charged specimens indicates a progression through a mix of ductile, intergranular, inter-dendritic and lattice cleavage failure modes as the hydrogen concentration in the Alloy 82 samples is increased. Both inter-granular and inter-dendritic modes have been observed during LTCP testing of Alloy 82 in literature [26]. Inter-granular fracture surfaces have been observed during in-situ LTCP testing in this study (Fig.17). As with the fractographs taken by Ahonen et al., the intergranular fracture surfaces in this study demonstrated nano-scale dimples and protrusions (Fig.17) that can be attributed to the presence of metal-carbides $[2,26,36]$. SEM and EDX of Alloy 82 cross sections taken during this study demonstrated that large $M C$ type carbides were present throughout the microstructure of the Alloy 82 material. These course and fine carbides are typically rich in $\mathrm{Nb}$, and have been observed within grains and along boundaries by other studies [2,4,26,36]. Fine chromium rich $\mathrm{M}_{23} \mathrm{C}_{6}$ type carbides form preferentially along inter-granular and inter-dendritic boundaries. As 
LTCP is an inter-granular and inter-dendritic failure mode this would indicate that chromium rich $\mathrm{M}_{23} \mathrm{C}_{6}$ type carbides are more detrimental.

LTCP proceeds via crack propagation along grain boundaries. During this process the influence of hydrogen should be considered in a number of ways. The hydrogen enhanced localised plasticity (HELP) theory describes hydrogen becoming trapped in dislocation cores. This has the effect of accelerating dislocation movement, but also transporting hydrogen towards grain boundaries. Results from this study (Fig.17), and in literature [26], have both shown the presence of slip traces on LTCP IG fracture surfaces. Optical microscopy of the ex-situ tensile specimens in this study demonstrated regions of strong localised deformation as the initiation points for the dominant cracks that lead to failure. In addition, all of the notched tensile specimens (both ex-situ charged and in-situ LTCP) showed evidence of plastic deformation prior to crack initiation or propagation.

This is indicative of local work hardening of the material, and a potential increase in the local hydrogen concentration as hydrogen absorbed at the crack surface is moved towards grain boundaries near the crack tip. In addition to this any hydrogen present in weak $\mathrm{M}_{23} \mathrm{C}_{6}$ trap sites, and potentially strong $\mathrm{MC}$ trap sites, is likely to be released by the strong tri-axial elastic strain field and the numerous dislocation strain fields near to the crack tip. 


\section{Conclusions}

- Novel ex-situ and in-situ mechanical testing clearly demonstrated the effect of hydrogen in assisting fracture of nickel based alloy 82 welds.

- For ex-situ charged tensile specimens hydrogen induced brittle fracture resulted in an elongation drop from $\sim 25 \%$ strain down to $\sim 2 \%$ strain with an increase in total hydrogen concentration of $>50$ wt.ppm. Specimens also demonstrated a reduction in the UTS from 595 $\mathrm{MPa}$ to $485 \mathrm{MPa}$, and a reduction in the NTS from $675 \mathrm{MPa}$ to $585 \mathrm{MPa}$.

- The reductions in the elongation to failure and the UTS were correlated with transitions from ductile to inter-granular, inter-dendritic, and cleavage brittle fracture modes.

- In-situ LTCP tests indicated a reduction in the load and displacement required for crack propagation, when tested in hydrogen enriched aqueous solution.

- The observed hydrogen embrittlement has been linked with the presence of trap sites such as chromium and niobium rich $\mathrm{MC}$ and $\mathrm{M}_{23} \mathrm{C}_{6}$ carbides. 
Figures

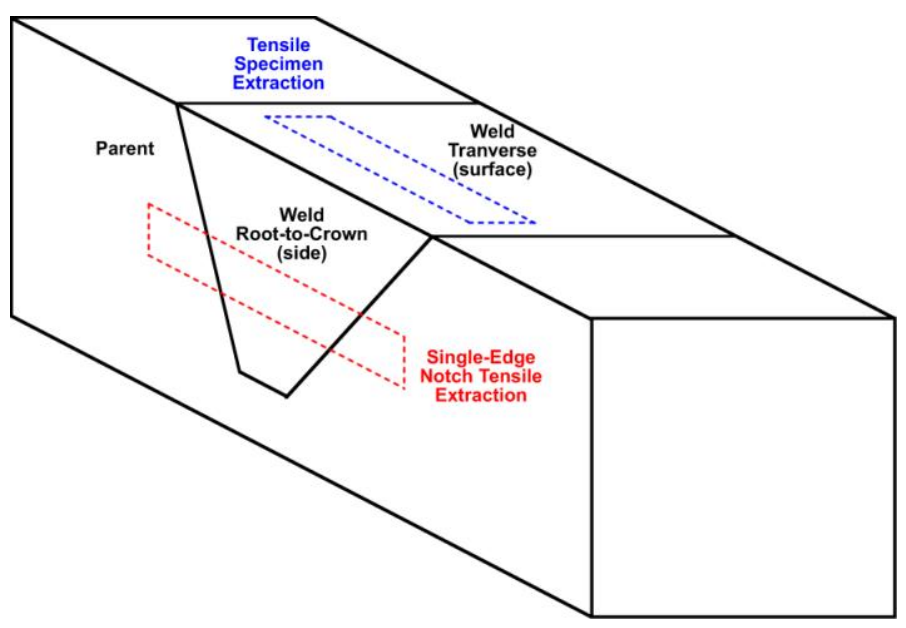

Figure 1: Schematic of the weld and specimen extraction orientations. 

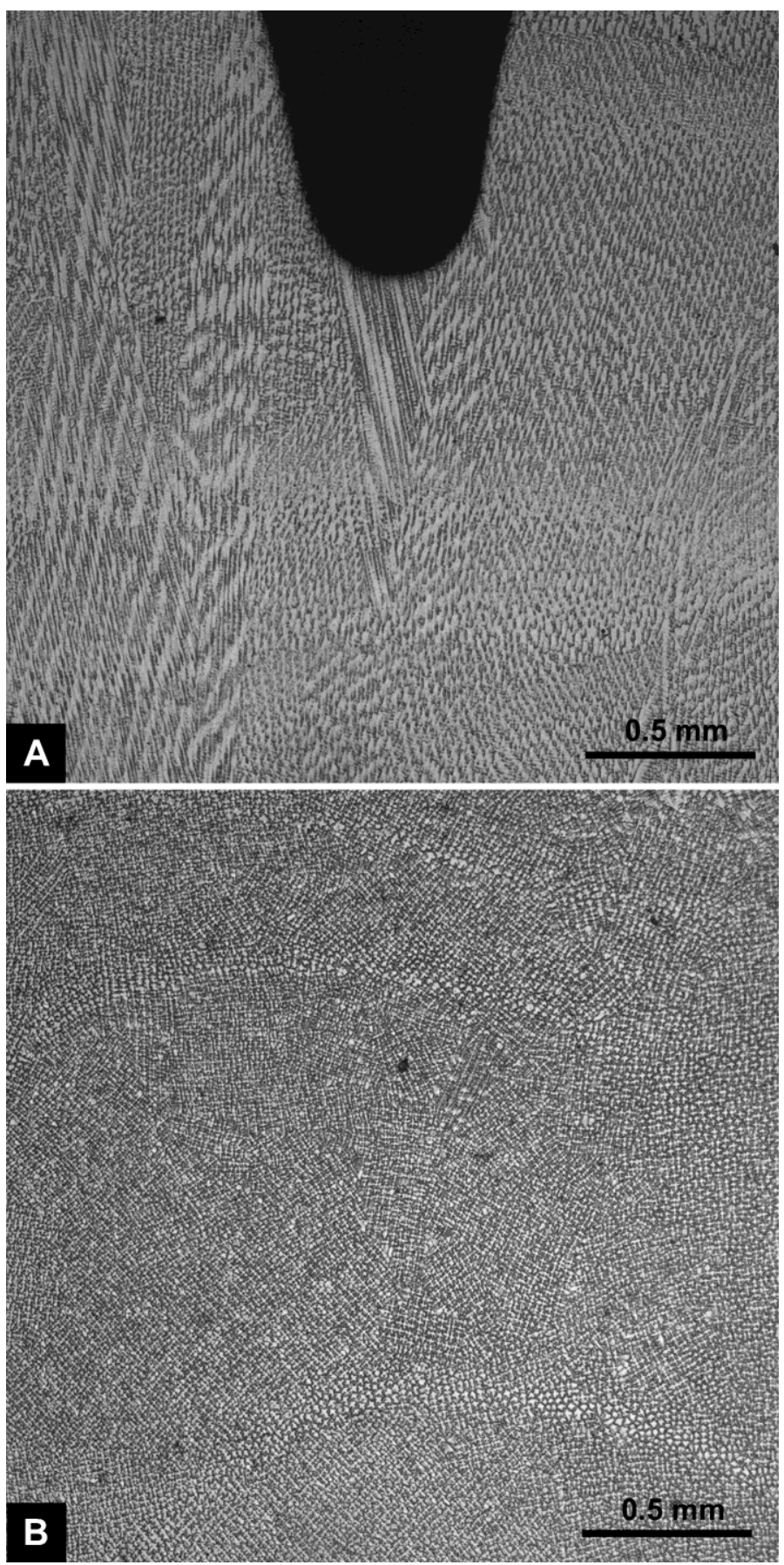

Figure 2: Optical microscopy of polished and etched sample showing the dendritic substructure the single edge notch samples and the root-to-crown direction $(A)$, and the tensile specimens and transverse direction (B) 

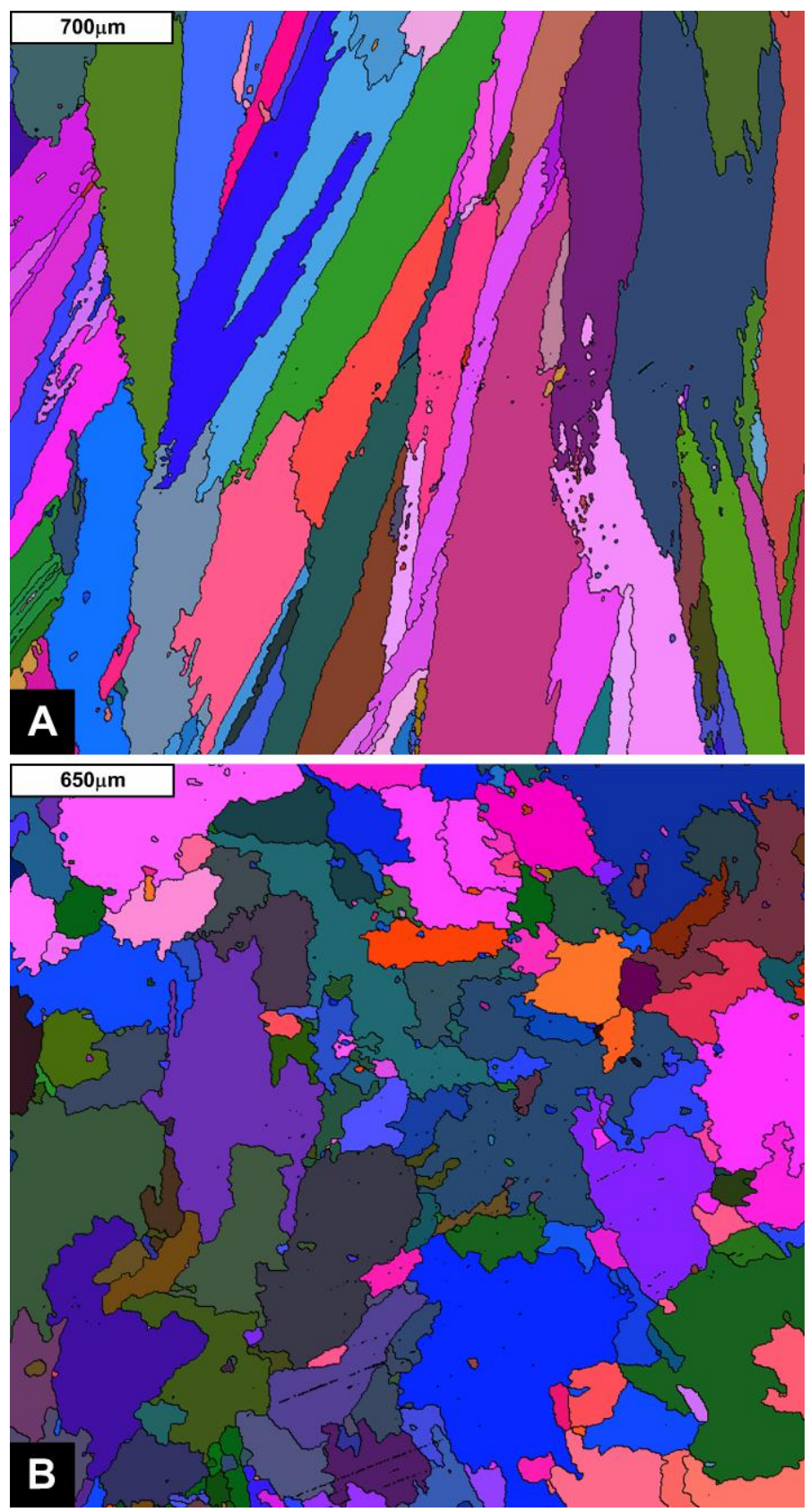

Figure 3: EBSD maps showing the grain morphology of the single edge notch samples and the root-tocrown direction (A), and the tensile specimens and transverse direction (B) 


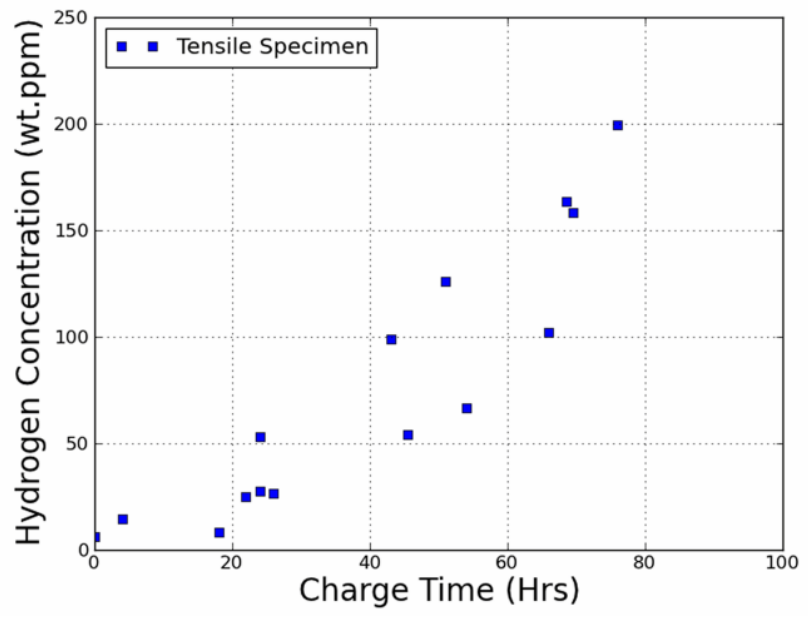

Figure 4: Total hydrogen concentration of Alloy 82 specimens for different charge times, charged in nitrogen purged $1 \mathrm{M} \mathrm{NaCl}$ at $\sim 75^{\circ} \mathrm{C}$ with an applied current density of $50 \mathrm{~mA} / \mathrm{cm}^{2}$.

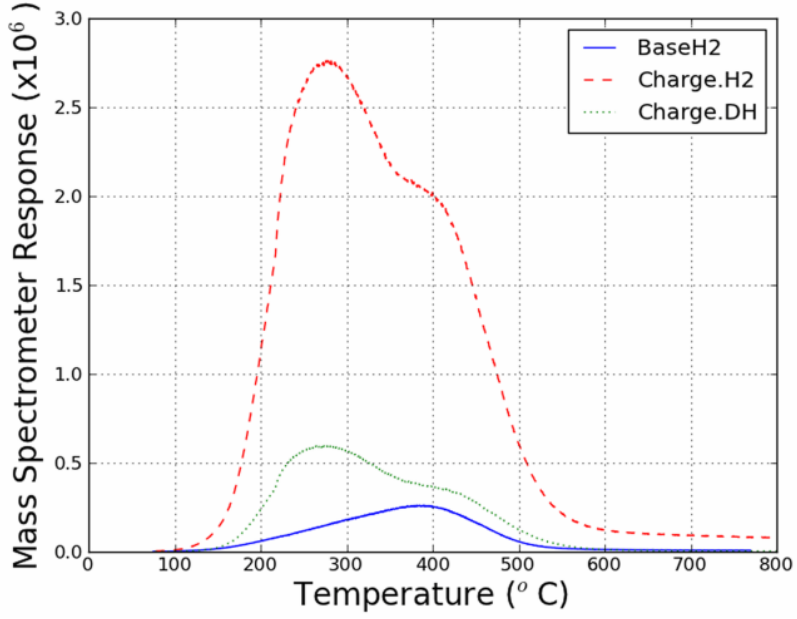

Figure 5: Mass response for hydrogen based molecules released from charged and uncharged specimens for increasing temperature. 


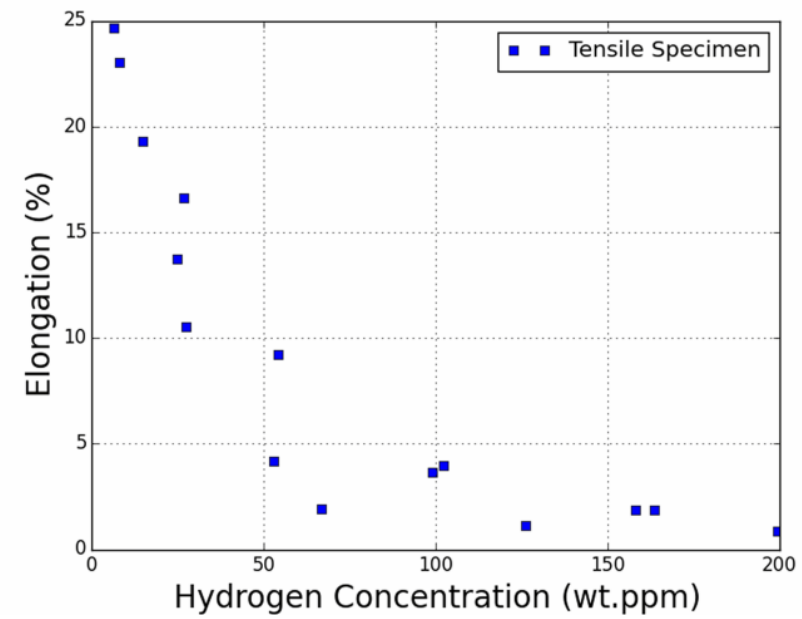

Figure 6: Plastic elongation plotted against total hydrogen concentration for the ex-situ hydrogen charged tensile specimens.
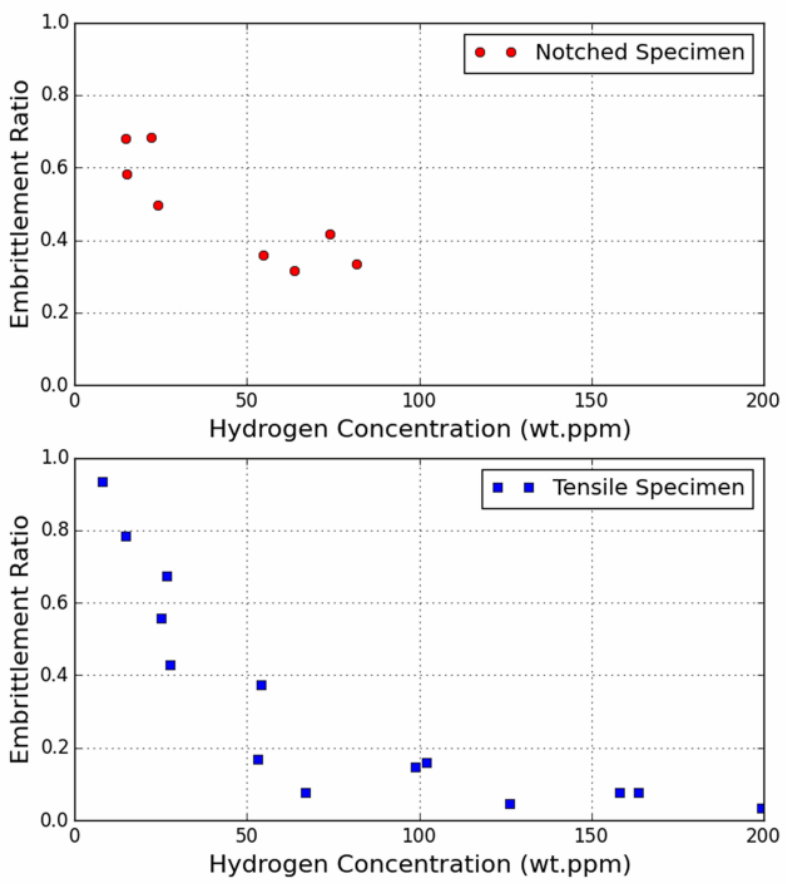

Figure 7: Embrittlement ratio based on plastic elongation plotted against total hydrogen concentration for the notched and tensile specimens. 


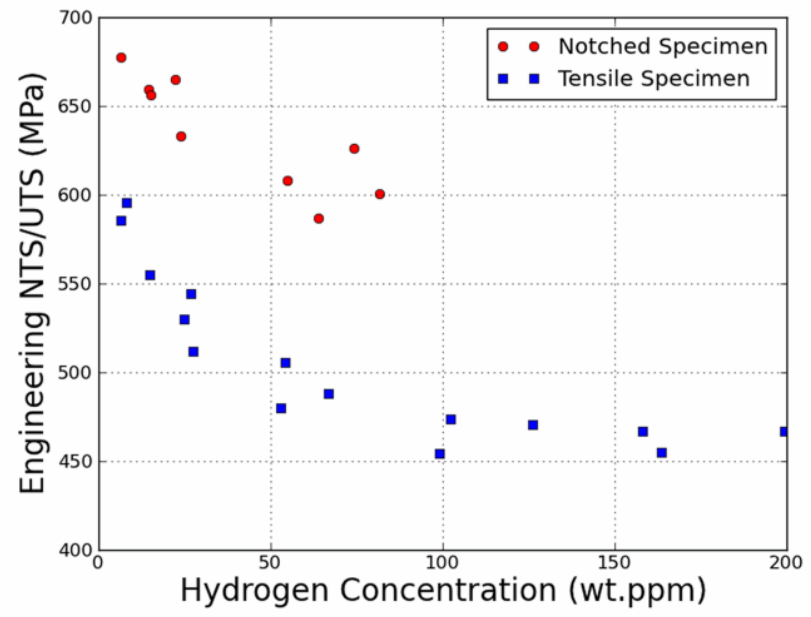

Figure 8: Engineering notched and ultimate tensile strength plotted against total hydrogen concentration for the notched and tensile specimens.
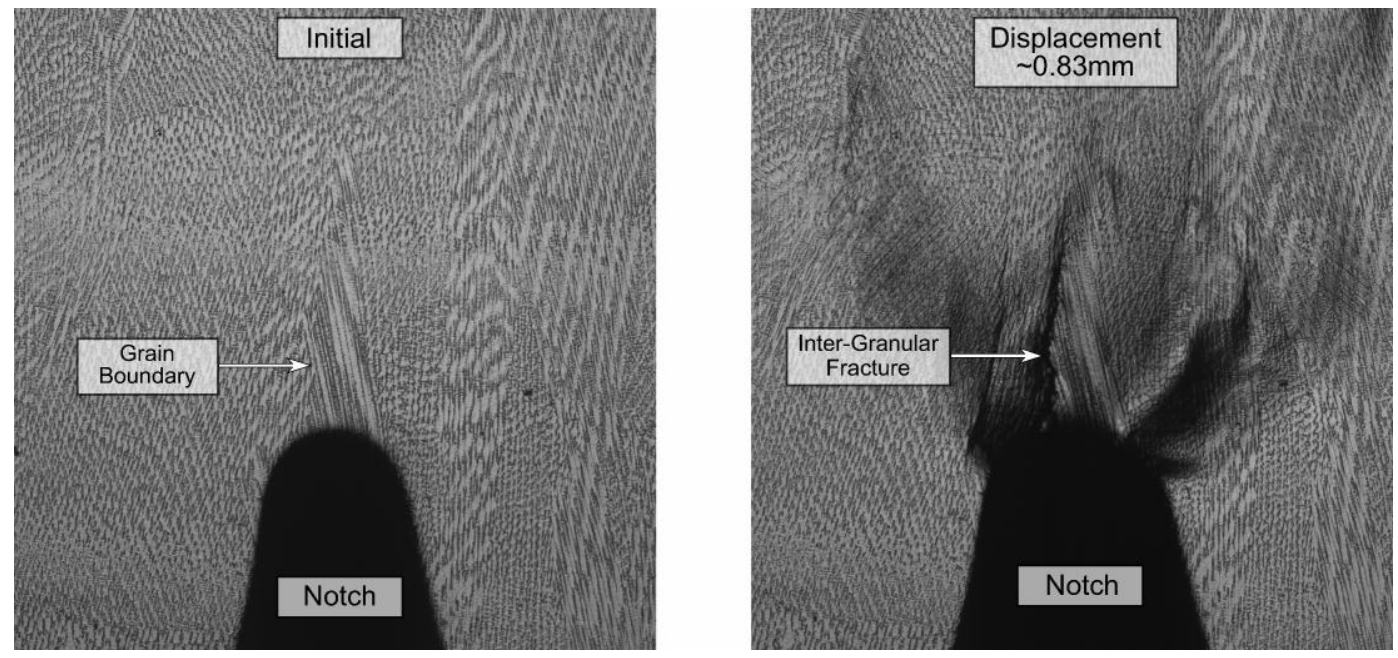

Figure 9: Optical images of an etched SENT specimen surface, charged to a total hydrogen concentration

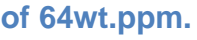



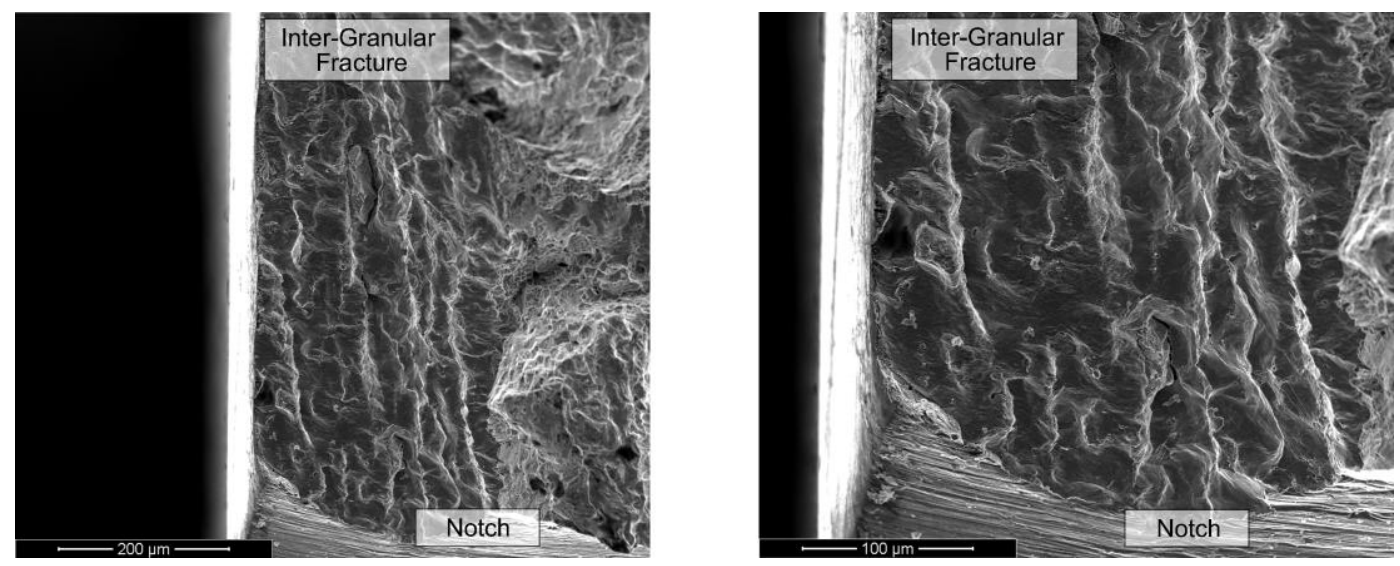

Figure 10: SEM images of the inter-granular fracture surface.
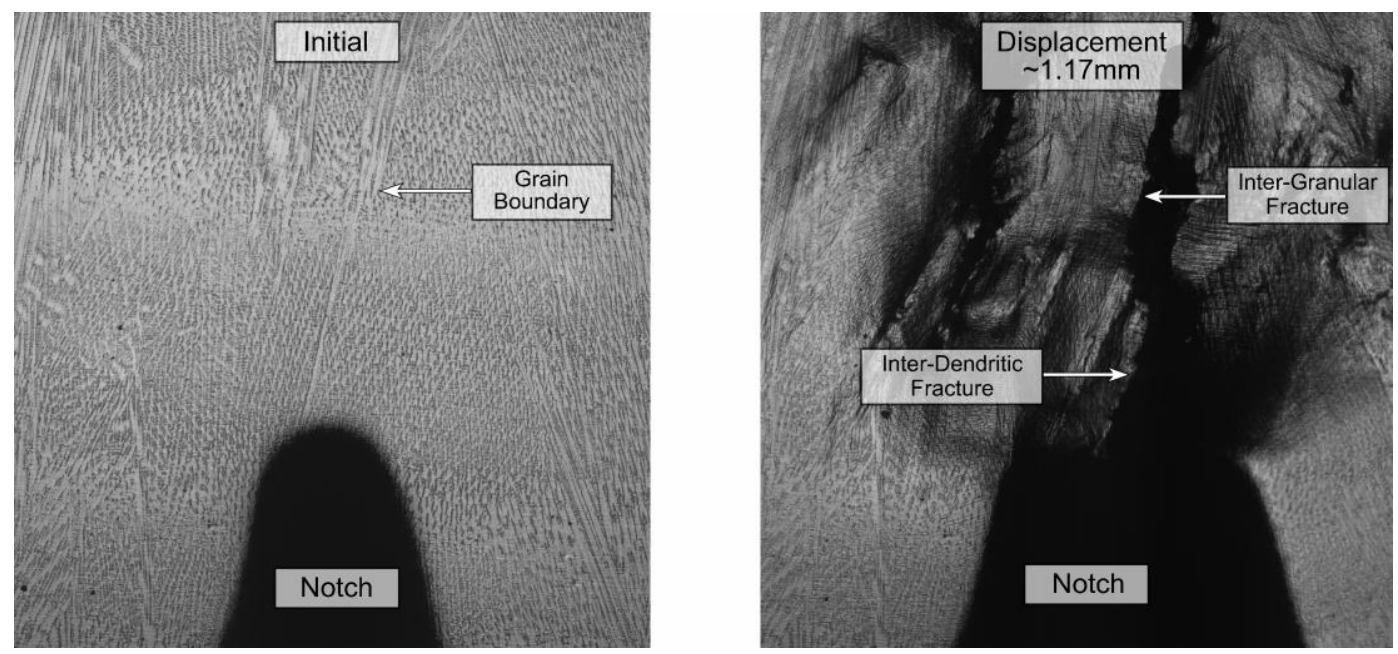

Figure 11: Optical images of an etched SENT specimen surface, charged to a total hydrogen concentration of 55wt.ppm. 

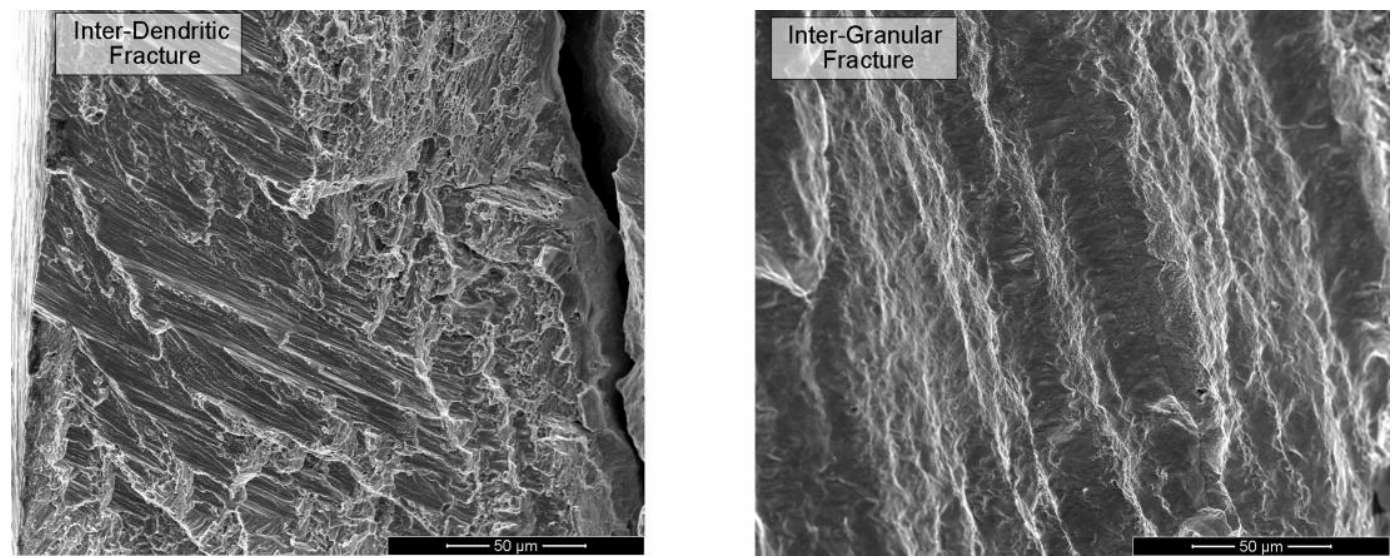

Figure 12: SEM images of the trans-granular/inter-dendritic and inter-granular fracture surfaces.

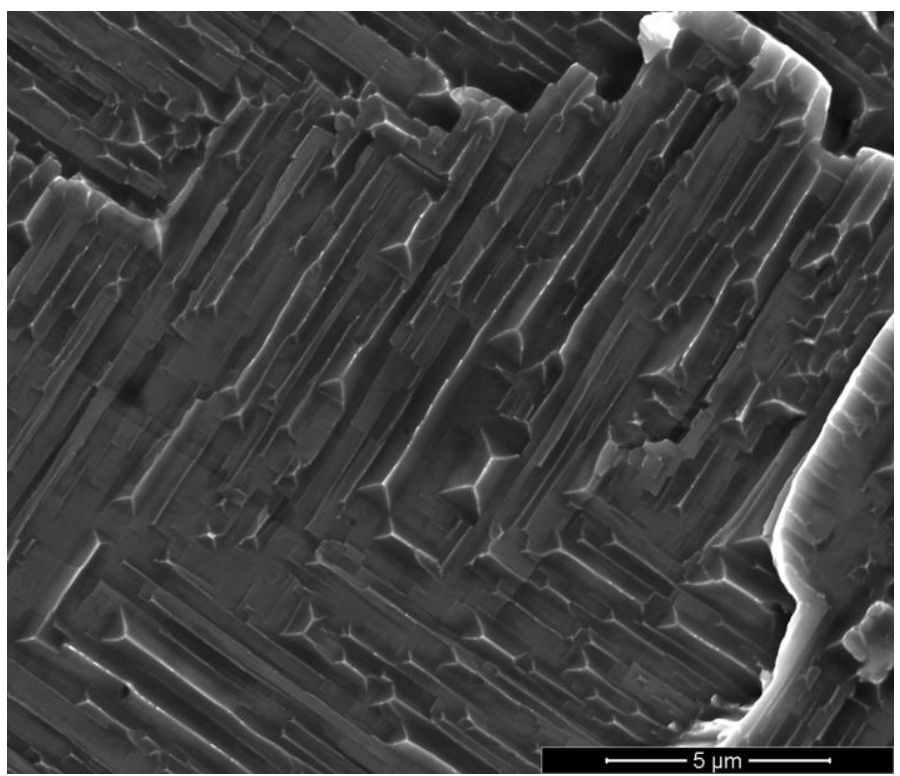

Figure 13: SEM of the fracture surface associated with the highest hydrogen concentrations, the appearance is indicative of something similar to cleavage fracture. 


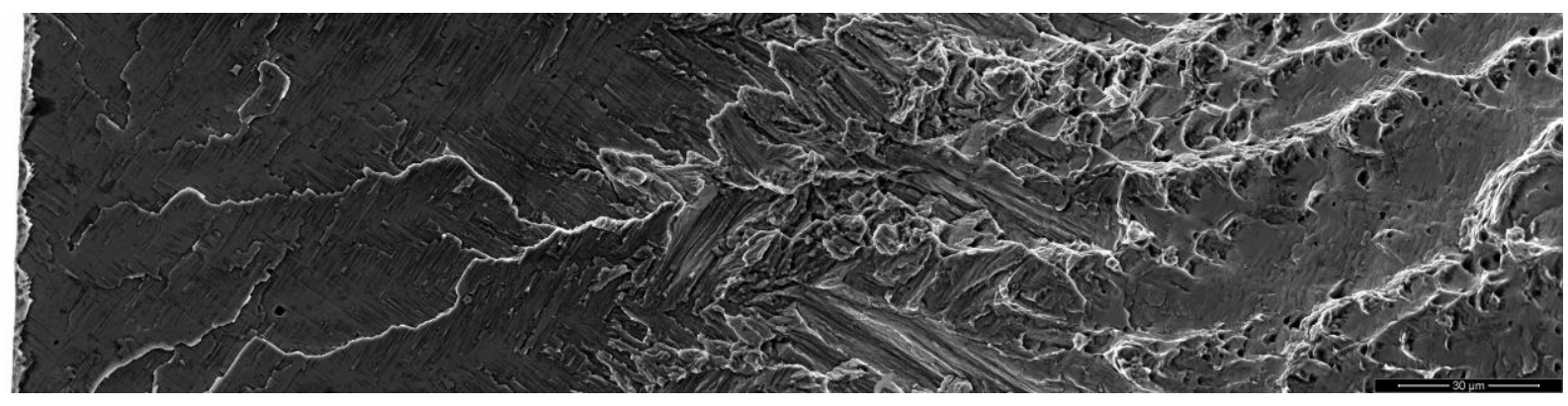

Figure 14: Stitched SEM image of the fracture surface for a sample charged with 126wt.ppm hydrogen. The sample surface is the left hand edge, demonstrating a transition from cleavage, to inter-dendritic and then inter-granular / dimpled ductile towards the right.

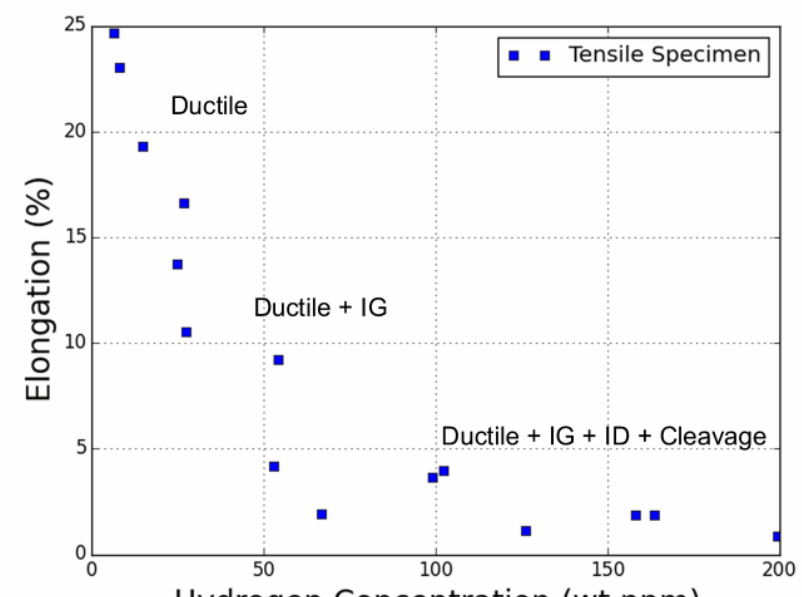

Hydrogen Concentration (wt.ppm)

Figure 15: Qualitative correlation between the observed fracture surfaces and the impact of hydrogen on the elongation.

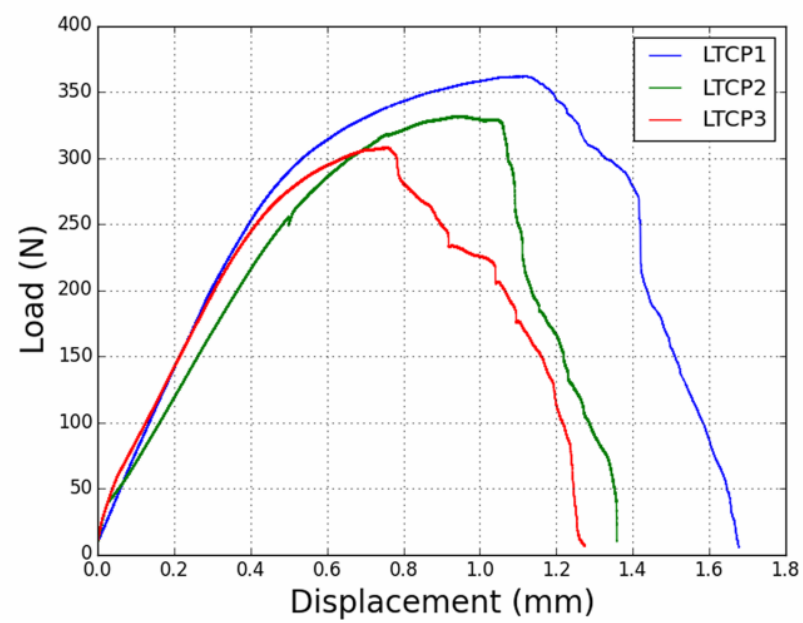

Figure 16: Summary of LTCP load-displacement data, all tests at $\sim 54{ }^{\circ} \mathrm{C}$, LTCP1 - nitrogen purged solution, LTCP2 - $69 \mathrm{cc} / \mathrm{kg} \mathrm{H}$ in solution \& $\sim 3$ day soak, LTCP3 - $69 \mathrm{cc} / \mathrm{kg} \mathrm{H}$ in solution \& $\sim 5$ day soak. 


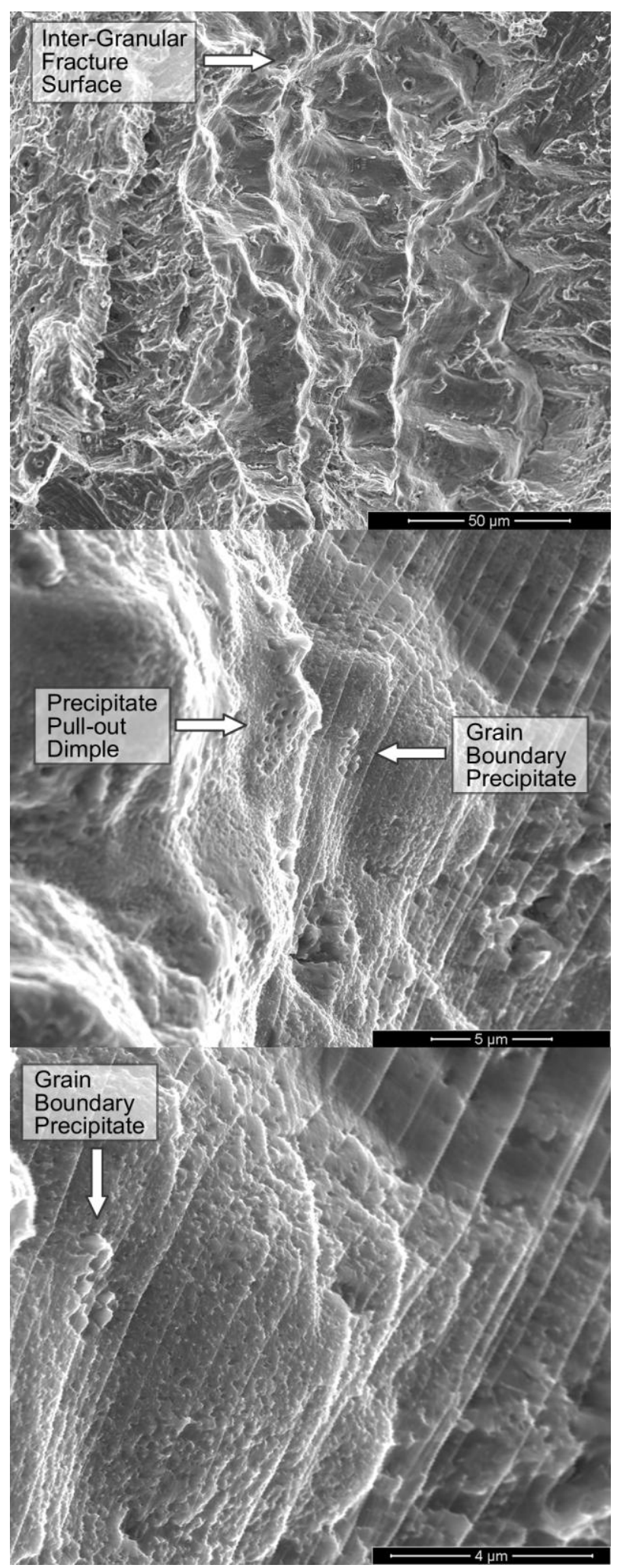

Figure 17: Inter-granular fracture surface of a sample tested in hydrogen rich water (LTCP3), with increasing magnification, highlighting precipitates and dimples. 


\section{References}

[1] S.R. Claves, W.J. Mills, Influence of Crystallographic Texture on Young's Modulus of Various Alloy 82H Welds, Microsc. Microanal. 17 (2011) 341-349. doi:10.1017/S1431927611000079.

[2] M. Sennour, E. Chaumun, J. Crepin, C. Duhamel, F. Gaslain, C. Guerre, I. de Curieres, TEM investigations on the effect of chromium content and of stress relief treatment on precipitation in Alloy 82, J. Nucl. Mater. 442 (2013) 262-269. doi:10.1016/j.jnucmat.2013.09.002.

[3] J.W. Kim, K. Lee, J.S. Kim, T.S. Byun, Local mechanical properties of Alloy 82/182 dissimilar weld joint between SA508 Gr.1a and F316 SS at RT and 320degC, J. Nucl. Mater. 384 (2009) 212-221. doi:10.1016/j.jnucmat.2008.11.019.

[4] W.J. Mills, C.M. Brown, Fracture toughness of alloy 600 and an EN82H weld in air and water, Metall. Mater. Trans. A. 32 (2001) 1161-1174. doi:10.1007/s11661-001-0126-6.

[5] W.J. Mills, C.M. Brown, Fracture Behavior of Nickel-Base Alloys in Water Report B-T-3240, 1999.

[6] C.M. Brown, W.J. Mills, Effect of water on mechanical properties and stress corrosion behavior of alloy 600, alloy 690, EN82H welds, and EN52 welds, Corrosion. 55 (1999) 173-186. doi:10.5006/1.3283978.

[7] B. Young, Low-Temperature Cracking of Nickel- Based Alloys and Weld Metals ( MRP-108), 2004.

[8] A. Mcllree, Materials Reliability Program Low Temperature Hydrogen Cracking of Ni-Based Weld Materials (MRP-145) 1011810, Palo Alto, CA, 2005.

[9] M. Ahonen, Effect of microstructure on low temperature hydrogen- induced cracking behaviour of nickel-based alloy weld metals, Aalto University, 2015.

[10] K. Sakima, H. Suzuki, H. Fujiwara, RESEARCH AND EVALUATION OF LOW TEMPERATURE CRACK PROPAGATION OF Ni BASE ALLOYS IN ACTUAL PLANTS, in: 15th Int. Conf. Environ. Degrad. Mater. Nucl. Power Syst., 2011: pp. 315-326.

[11] M. Ahonen, Collation of LTCP Test Results Obtained in Years 2008-2012, 2012.

[12] C.M. Brown, W.J. Mills, Fracture toughness of alloy 690 and EN52 welds in air and water, Metall. Mater. Trans. A. 33 (2002) 1725-1735. doi:10.1007/s11661-002-0181-7.

[13] M. Ahonen, U. Ehrnsten, H. Hanninen, LOW TEMPERATURE CRACK PROPAGATION OF NICKEL-BASED WELD METALS IN HYDROGENATED PWR PRIMARY WATER, in: Fontevraud 7, 2010.

[14] E. Herms, O. Raquet, I. De Curières, P. Joly, LTCP OF ALLOY 182 / 152 TESTED IN PWR PRIMARY WATER, in: 14th Int. Conf. Envrionmental Degrad. Mater. Nucl. Power Syst., 2009: pp. 262-272.

[15] M. Ahonen, U. Ehrnstein, T. Saukkonen, O. Todoshchenko, H. Hanninen, Environmental influence on cracking susceptiblity and aging on nuclear materials (ENVIS), special article report: Low Temperature Crack Propagation (LTCP) susceptibility of nickel-based Alloy 182, 152, 82 and 52 weld metals in PWR primary water, in: SAFIR 2014 Semin., 2015: pp. 1-19.

[16] W.J. Mills, M.R. Lebo, J.J. Kearns, Hydrogen embrittlement, grain boundary segregation, and stress corrosion cracking of alloy X-750 in low-and high-temperature water, Metall. Mater. Trans. A. 30 (1999) 1579-1596. doi:10.1007/s11661-999-0095-8.

[17] T. Kubo, N. Saito, H. Sakamoto, S. Tanaka, Evaluation of sensitization of Ni-base weld metal by the EPR method, in: 10th Int. Conf. Environ. Degrad. Mater. Nucl. Power Syst. Water React., 2001.

[18] T.H. Lee, I.S. Hwang, H.D. Kim, J.H. Kim, Techniques for intergranular crack formation and assessment in alloy 600 base and alloy 182 weld metals, Nucl. Eng. Technol. 47 (2015) 102-114. doi:10.1016/j.net.2014.08.002.

[19] B. Alexandreanu, O.K. Chopra, W.J. Shack, The Effect of Grain Orientation on the Cracking Behavior of Alloy 182 in PWR Environment, in: Proc. 12th Int. Conf. Environ. Degrad. Mater. Nucl. Power Syst. - Water React. -, 2005. 
[20] N. Takano, S. Kaida, Crack Initiation by Cathodic Hydrogen Charging in Nickel Single Crystal, ISIJ Int. 52 (2012) 263-266. doi:10.2355/isijinternational.52.263.

[21] O.A. El kebir, A. Szummer, Comparison of hydrogen embrittlement of stainless steels and nickel-base alloys, Int. J. Hydrogen Energy. 27 (2002) 793-800. doi:10.1016/S03603199(01)00151-3.

[22] Y. Yao, X. Pang, K. Gao, Investigation on hydrogen induced cracking behaviors of Ni-base alloy, Int. J. Hydrogen Energy. 36 (2011) 5729-5738. doi:10.1016/j.ijhydene.2011.01.123.

[23] M. Wang, E. Akiyama, K. Tsuzaki, Effect of hydrogen and stress concentration on the notch tensile strength of AISI 4135 steel, Mater. Sci. Eng. A. 398 (2005) 37-46. doi:10.1016/j.msea.2005.03.008.

[24] S.R. Claves, D.J. Paraventi, W.J. Mills, Characterization of Alloy 82H GTA Welds for SCC Studies and Structural Analyses, Microsc. Microanal. 18 (2012) 1348-1349. doi:10.1017/S1431927612008598.

[25] S.R. Claves, EBSD Microstructural Characterization of Various Alloy 82H GTA Weld Configurations: Butt Joints, Build-ups, and Overlays, Microsc. Microanal. 18 (2012) 1664-1665. doi:10.1017/S1431927612010173.

[26] M. Ahonen, Effect of microstructure on low temperature hydrogen induced cracking behaviour of nickel-based alloy weld metals, 2015.

[27] M. Koyama, H. Springer, S. V. Merzlikin, K. Tsuzaki, E. Akiyama, D. Raabe, Hydrogen embrittlement associated with strain localization in a precipitation-hardened Fe-Mn-Al-C light weight austenitic steel, Int. J. Hydrogen Energy. 39 (2014) 4634-4646. doi:10.1016/j.jijhydene.2013.12.171.

[28] M. Koyama, E. Akiyama, K. Tsuzaki, D. Raabe, Hydrogen-assisted failure in a twinninginduced plasticity steel studied under in situ hydrogen charging by electron channeling contrast imaging, Acta Mater. 61 (2013) 4607-4618. doi:10.1016/j.actamat.2013.04.030.

[29] Y.S. Lim, J.S. Kim, H.P. Kim, H.D. Cho, The effect of grain boundary misorientation on the intergranular M 23C6 carbide precipitation in thermally treated Alloy 690, J. Nucl. Mater. 335 (2004) 108-114. doi:10.1016/j.jnucmat.2004.07.038.

[30] A. Turnbull, A.T. May, The effect of temperature and H2S content on the cracking resistance of a 13\% chromium martensitic stainless steel in acidified $\mathrm{NaCl}$, Corros. Sci. 30 (1990) 657-665. doi:10.1016/0010-938X(90)90030-9.

[31] Q. Liu, A. Atrens, A critical review of the influence of hydrogen on the mechanical properties of medium-strength steels, Corros. Rev. 31 (2013) 85-103. doi:10.1515/corrrev-2013-0023.

[32] C. Ayas, V.S. Deshpande, N.A. Fleck, A fracture criterion for the notch strength of high strength steels in the presence of hydrogen, J. Mech. Phys. Solids. 63 (2014) 80-93. doi:10.1016/j.jmps.2013.10.002.

[33] M. Koyama, E. Akiyama, K. Tsuzaki, D. Raabe, Hydrogen-assisted failure in a twinninginduced plasticity steel studied under in situ hydrogen charging by electron channeling contrast imaging, Acta Mater. 61 (2013) 4607-4618. doi:10.1016/j.actamat.2013.04.030.

[34] F. Galliano, E. Andrieu, C. Blanc, J.M. Cloue, D. Connetable, G. Odemer, Effect of trapping and temperature on the hydrogen embrittlement susceptibility of alloy 718 , Mater. Sci. Eng. A. 611 (2014) 370-382. doi:10.1016/j.msea.2014.06.015.

[35] P.D. Hicks, C.J. Altstetter, Hydrogen-enhanced cracking of superalloys, Metall. Trans. A. 23 (1992) 237-249. doi:10.1007/BF02660868.

[36] M. Wehbi, T. Couvant, C. Duhamel, J. Crepin, Oxidation of nickel-base welds 182 and 82 in simulated primary water of pressurised water reactors, Mater. High Temp. 32 (2015) 1-9. doi:10.1179/1878641314Y.0000000031. 